\title{
FENOMENOLOGIA DE EDMUND HUSSERL E DIREITO: CAMINHOS E OBSTÁCULOS
}

\section{EDMUND HUSSERL'S PHENOMENOLOGY AND LAW: PATHWAYS AND OBSTACLES}

\author{
Anselmo Laghi Laranja \\ Faculdade de Direito de Vitória - FDV - (Vitória, ES, Brasil) \\ Tribunal de Justiça do Estado do Espírito Santo (Vitória, ES, Brasil) \\ Elda Coelho de Azevedo Bussinguer \\ Faculdade de Direito de Vitória - FDV - (Vitória, ES, Brasil)
}

Recebimento: 18 jan. 2018

Aceitação: 2 mar. 2018

Como citar este artigo / How to cite this article (informe a data atual de acesso / inform the current date of access):

LARANJA, Anselmo Laghi; BUSSINGUER, Elda Coelho de Azevedo. Fenomenologia de Edmund Husserl e Direito: caminhos e obstáculos. Revista da Faculdade de Direito UFPR, Curitiba, PR, Brasil, v. 63, n. 1, p. 189-212, abr. 2018. ISSN 2236-7284. Disponível em: <http://revistas.ufpr.br/direito/article/view/57291>. Acesso em: 30 abr. 2018. DOI: http://dx.doi.org/10.5380/rfdufpr.v63i1.57291.

\section{RESUMO}

O presente artigo tem como objetivo analisar quais são os obstáculos a serem enfrentados pelo pesquisador do Direito com a utilização do método fenomenológico de Edmund Husserl. Para isso, são expostos três aspectos que permeiam a questão: (i) o papel que a fenomenologia possuiu no declínio do positivismo entre os séculos XIX e XX, demonstrando as questões que o positivismo não conseguiu responder e as respostas apresentadas, como contrapartida, pela fenomenologia; (ii) as contribuições da fenomenologia para o estudo do Direito, principalmente em relação aos problemas do conceito de Direito e os métodos de interpretação da norma; (iii) os obstáculos que surgiram da influência da fenomenologia e as questões deles decorrentes, que precisam ser respondidas visando ao desenvolvimento da ciência jurídica. Como conclusão, foram considerados como principais obstáculos a dificuldade de transparência do método fenomenológico, de verificabilidade dos seus resultados e de adaptação de suas premissas à mutabilidade do Direito como fenômeno social.

\section{PALAVRAS-CHAVE}

Fenomenologia. Edmund Husserl. Metodologia. Método fenomenológico. Direito.

\section{ABSTRACT}

The objective of this paper is to assess what obstacles are to be faced by the law researcher when using Edmund Husserl's phenomenological method. For such, three aspects related to these issues are exposed, namely: (i) the role phenomenology played in the decline of positivism in the nineteenth and twentieth centuries, showing the questions that remained unanswered by positivism and the answers presented, in contrast, by phenomenology; (ii) the contributions of phenomenology to the study of law, particularly regarding issues related to the concept of law and the rule interpretation; (iii) the obstacles arising from the influence of phenomenology and the questions then ensued, which need to be answered for the sake of development of legal science. As a conclusion, the main obstacles 
to be considered were the phenomenological method's lack of transparency, the absence of verifiability regarding its results and the difficulty in adapting its premises to the mutability of the law as a social phenomenon.

\section{KEYWORDS}

Phenomenology. Edmund Husserl. Methodology. Phenomenological method. Law.

\section{INTRODUÇÃO}

No transcurso da história humana, diversas foram as modalidades de relacionamento entre o homem e o conhecimento. Com base nas três tradicionais perguntas da filosofia antiga - "Quem sou?”, “De onde vim?” e "Para onde vou?” - o homem tem se deparado com diversas formas de resposta para o desconhecido, seja por meio da mitologia, da religião, da filosofia ou da ciência.

Cada uma dessas formas de abordagem dos problemas humanos traz sua estrutura peculiar, com suas premissas e seus objetivos. Isso faz com que o estudo desse relacionamento entre o homem e o conhecimento ganhe relevância e que o "método" torne-se um objeto próprio de pesquisa.

Do grego antigo, "método" é formado pelo prefixo "meta-" e pela palavra "hódos". O primeiro transmite a ideia de intermediação, um "através de”, enquanto a segunda significa “caminho", "via”. Assim, "método”, em sua origem, constitui uma "ordem que se segue na investigação da verdade, no estudo de uma ciência ou para alcançar um fim determinado” (CUNHA, 2010, p. 423-424).

O problema do “método”, portanto, torna-se uma questão metalinguística, que abarca toda a complexidade que essa característica possui. Um dos desafios dessa complexidade é o problema do regresso ao infinito, pensamento que faria supor que sempre é necessário um “metamétodo” para se analisar um método. Disso surge a necessidade de que o método sempre dialogue com uma base teórica, que colocará os pressupostos nos quais ele se funda.

Por conta disso, não existe método que não esteja influenciado pelo estágio de desenvolvimento epistemológico do contexto em que foi criado, bem como pelas premissas filosóficas que permitiram que ele se sustentasse como legítimo “caminho” para a aquisição de conhecimento.

Essa observação permitiu que se desenvolvesse outro ramo para o estudo do relacionamento entre o ser humano e o conhecimento: a filosofia da ciência. Reale e Antiseri (2001, p. 5), nesse sentido, repetem as palavras de Benedetto Croce sobre o desenvolvimento das teorias filosóficas: “Nenhum sistema filosófico é definitivo, porque a própria vida não é definitiva. Um sistema filosófico 
resolve um grupo de problemas historicamente dado e prepara as condições para a proposição de outros problemas, isto é, de novos sistemas. Sempre foi e sempre será assim.”

Esse pensamento de Croce é particularmente relevante porque enfatiza dois aspectos que podem ser considerados de suma importância para o estudo dos diversos métodos de pesquisa: (i) o papel do pesquisador na busca por respostas aos problemas que afligem sua época e (ii) a limitação que o conhecimento humano possui.

Esses dois aspectos criam um parâmetro de análise capaz de tornar o estudo das diversas matrizes metodológicas algo além da mera aquisição de termos rebuscados ou nomes difíceis.

A busca por entender como uma determinada metodologia encontrou meios para responder aos problemas que os pesquisadores de sua época enfrentavam - bem como reconhecer que esses meios não esgotam a realidade - permite ao pesquisador contemporâneo tomá-la como exemplo ao se deparar com questões parecidas, mas também criticar aqueles sistemas que vigem em seu tempo, expondo os obstáculos que eles possuem e os novos problemas que deles advieram.

Isso não é diferente com o estudo do Direito. Na verdade, a ciência jurídica insere-se integralmente nesse debate. Assim como as demais áreas do conhecimento, a ciência jurídica precisa de um método e de uma base teórica apropriados para construir a racionalidade que guiará os agentes do sistema jurídico, principalmente no que tange a dois problemas muito caros ao estudo do Direito: (i) o objeto de pesquisa e (ii) os métodos de interpretação desse objeto.

Com relação ao objeto de pesquisa, a ciência jurídica tem como principal desafio entender quais são as fontes do Direito, ou seja, aqueles elementos capazes de transmitir dados com caráter jurídico, com normatividade. Isso implica saber o que é o Direito. Por conseguinte, esses dados também são objeto de algum modelo de interpretação, que pode ser das mais diversas formas, como a exegese ou o construtivismo lógico-semântico.

Apenas na medida em que se sabe das diversas possibilidades de interação entre base teórica e método, bem como o que cada um desses arranjos tem a contribuir e a obstaculizar, é possível pensar em uma atividade de pesquisa consciente.

Assim, para contribuir com a análise das possibilidades e limites dos sistemas filosóficos que existem, o presente artigo tem como objetivo analisar uma das principais matrizes metodológicas e filosóficas da contemporaneidade, a fenomenologia. A escolha dessa abordagem de pesquisa como objeto de estudo deriva de se acreditar ser possível observar sua influência em uma série de práticas do pesquisador do Direito contemporâneo, mas também porque é possível delinear algumas questões que sua utilização levanta. Com isso, partindo da premissa de que toda matriz filosófica possui limites 
cognoscitivos, o presente artigo busca responder à seguinte pergunta: quais os obstáculos que precisam ser enfrentados pelo pesquisador do Direito com a utilização do método fenomenológico?

Em decorrência do alto nível de diversidade de pensamento que os membros dessa corrente filosófica possuem, o objeto de pesquisa ficará limitado à fenomenologia de Edmund Husserl, por duas razões: (i) ser ela a origem comum dos demais pensadores fenomenólogos que a sucederam e (ii) apresentar uma estrutura de pensamento baseada na busca por elementos invariáveis a priori, que será o principal objeto de crítica da presente pesquisa.

A fenomenologia de Edmund Husserl não pode ser compreendida sem ser contextualizada e comparada com o principal movimento filosófico ao qual ele se opunha: o positivismo. "Os temas básicos da fenomenologia Husserliana apresentam-se, assim, no contexto de sua crítica ao psicologismo e ao empirismo" (CAPALBO, 1983, p. 5).

Por isso, esse artigo é dividido em três capítulos. No primeiro, serão apresentadas as características fundamentais da fenomenologia a partir do pensamento de seu precursor, Edmund Husserl, bem como algumas contraposições deste para com o positivismo. No segundo, será apresentado como as contribuições da fenomenologia têm influenciado o estudo do Direito, principalmente em relação aos problemas do conceito de Direito e aos métodos de interpretação da norma. Por último, o terceiro capítulo tem como objetivo apresentar os obstáculos que surgiram da influência da fenomenologia e os problemas daí decorrentes, que precisam ser resolvidos para o desenvolvimento da ciência jurídica.

\section{EDMUND HUSSERL E O REPOSICIONAMENTO DO PROBLEMA DO CONHECIMENTO}

Edmund Husserl foi o precursor do movimento fenomenológico. De origem judia, formouse pela Universidade de Viena e teve grande influência de dois pensadores: Bernhard Bolzano e Franz Brentano.

Nesse contexto, Bolzano (1781-1848) produziu, na sua obra a Doutrina da Ciência (1837), a teoria da “proposição em si”, segundo a qual “a proposição em si é o puro significado lógico de um enunciado, não dependendo do fato de ele ser expresso ou pensado”. Defendeu uma “verdade em si”, de forma que os princípios lógicos possuíam validade objetiva e alheia à consciência humana (REALE; ARSINI, 2001, p. 177).

Enquanto isso, Brentano (1838-1917), professor da Universidade de Viena, propôs, na obra A psicologia do ponto de vista empírico (1874), uma mudança de método no estudo do psiquismo. 
Para ele, os fenômenos físicos deveriam ser distinguidos dos fenômenos psíquicos, que, por sua vez, possuíam um modo de percepção próprio capaz de demostrar seu conhecimento fundamental (DARTIGUES, 2008, p. 15). A essa característica peculiar dos fenômenos psíquicos ele chamou de intencionalidade da consciência. Baseando-se na escolástica ${ }^{1}$, entendia o termo intentio como aquele elemento que indica algo diferente de si (RIBEIRO JÚNIOR, 2003, p. 20-21). Nada obstante, a escola de Brentano ainda era demasiadamente vinculada à ideia de separação entre sujeito e objeto. Husserl irá além e, negando a dicotomia kantiana “fenômeno” e “coisa em si”, considerará que “a consciência se define essencialmente em termos de intenção voltada para um objeto” (CAPALBO, 2008, p. 1819).

Indo de encontro ao forte ambiente cientificista presente, à época, na Europa, Husserl construirá a fenomenologia tecendo vigorosa crítica ao psicologismo, corrente que entendia que “os princípios diretores do conhecimento não são senão a resultante de leis biológicas, psicológicas ou sociológicas” (DARTIGUES, 2008, p. 17). Para ele, o intelecto não é apenas o conjunto de eventos físico-fisiológicos que ocorrem nas redes neurais, tampouco a teoria do conhecimento deve ser entendida como "uma descrição do comportamento do sujeito na atividade de conhecer”, como queriam os naturalistas (CHAUÍ, 1979, p. VI).

Ao interpretar a obra mais famosa de Husserl, Investigações Lógicas (1975), Chauí demonstra a influência que os professores dele tiveram na formação de seu pensamento. A partir de Bolzano, defende que “as leis lógicas, sustentáculos da unidade de toda ciência, não podem [...] fundamentar-se na psicologia” (CHAUÍ, 1979, p. VI), em dados da experiência. Sob outra perspectiva, o que Husserl faz é demonstrar que os elementos que são a base na unicidade científica não se baseiam no conhecimento científico.

Dessa forma, sustentará que o psíquico não é coisa (mecanismos cerebrais e nervosos), mas fenômeno. Ao passo que a coisa é o "fato exterior, empírico, governado por relações causais e mecânicas, [...] o fenômeno é a consciência, enquanto fluxo temporal de vivências e cuja peculiaridade é a imanência e a capacidade de outorgar significado às coisas exteriores” (CHAUÍ, 1979, p. VI-VII). Isso não significa que Husserl nega o conhecimento advindo da análise empírica da consciência, que a entende como coisa. Sua posição é de que essa interpretação não é absoluta, tampouco tem primazia (CHAUÍ, 1979, p. VII).

\footnotetext{
${ }^{1}$ Conforme Abbagnano (2007, p. 344), o termo escolástica se refere à filosofia de cunho cristão da Idade Média. “O problema fundamental da [Escolástica] é o exercício da atividade racional [...] com vistas ao acesso à verdade religiosa”.
} 
No momento em que recolocou o problema do conhecimento (o conhecimento enquanto fenômeno), Husserl atribuiu um novo significado ao termo fenômeno. O sentido comum de fenômeno sugere entendê-lo como aparência sensível que manifesta a realidade ou como aparência sensível que se contrapõe ao fato (ABBAGNANO, 2007, p. 436). Assim, entendem-se os fenômenos físicos como manifestações da realidade e os fenômenos de ótica como “ilusões” que não correspondem aos fatos. Esse sentido de fenômeno pode ser encontrado em Bacon, Descartes, Hobbes e Wolff (ABBAGNANO, 2007, p. 437). Esse não é o significado de Husserl.

No século XVIII, o termo fenômeno ganha uma segunda significação, que se deve a Kant. Para ele, fenômeno representa “o objeto específico do conhecimento humano que aparece sob condições particulares, características da estrutura cognoscitiva do homem” (ABBAGNANO, 2007, p. 437). A teoria kantiana se baseia na ideia de que a coisa em si (o objeto puro) é incognoscível ao homem. O conhecimento humano seria, desse modo, um conhecimento que já vem filtrado pelas categorias analíticas propriamente humanas (KANT, 2001, p. 22). Assim, o fenômeno seria o conhecimento que, já tendo passado pelos “filtros” do intelecto humano, é cognoscível e aparece ao homem (ADEODATO, 2013, p. 68). Há, portanto, uma clara distinção entre fenômeno e “coisa em si” (ou númeno) (ABBAGNANO, 2007, p. 437). Esse também não é o sentido dado a fenômeno por Husserl.

O terceiro sentido, ao qual Husserl se vinculou, conceitua fenômeno como "aquilo que se manifesta em si mesmo, como é em si, na sua essência” (ABBAGNANO, 2007, p. 437). Isso não representa um retorno ao primeiro sentido, como correspondência da realidade (fenômeno físico). Husserl entende que o fenômeno "não é uma manifestação natural ou espontânea da coisa: exige outras condições, que são impostas pela investigação filosófica como fenomenologia” (ABBAGNANO, 2007, p. 437). Os fenômenos que a fenomenologia husserliana estuda "não são os fenômenos reais do mundo, mas sim os fenômenos que sofreram reduções transcendentais e que Husserl chamará de fenômenos irreais” (CAPALBO, 2008, p. 50).

Por essa razão, aproxima-se do sentido kantiano, mas não se esgota nele. Husserl acaba com a oposição que Kant havia criado entre fenômeno e "coisa em si”, passando a entendê-lo como “o em si da coisa em sua manifestação, não constituindo, pois, uma aparência da coisa, mas identificandose com seu ser” (ABBAGNANO, 2007, p. 437).

Por conta disso, a fenomenologia pode ser entendida enquanto "uma ciência a priori e universal porque descreve essências (isto é, objetos ideais e não empíricos). É universal, porque se refere a todas as vivências” (RIBEIRO JÚNIOR, 2003, p. 12). Sendo ela mesma o questionamento primeiro acerca das essências, ela também pode ser entendida enquanto “caminhada rumo às coisas 
mesmas. Faz-se enquanto tentativa de garantir a autenticidade do pensar, sem a obrigatoriedade de referencial que a priori a explique ou justifique” (BUSSINGUER, 2012, p. 70).

O sentido da segunda parte desse conceito advém de outra crítica que o movimento fenomenológico faz à ciência positiva. A fenomenologia critica o fato de a ciência produzir conhecimento a partir de dogmas inquestionáveis, sendo que o mais evidente deles é o da crença no mundo exterior e no conhecimento transcendente.

A ciência positiva parte da premissa empirista de que o ser humano é como uma tábula rasa, uma folha em branco, que, à medida que experimenta o mundo, recebe o conhecimento que dele advém. Assim, já pressupõe a existência de objetos alheios ao homem como um dado evidente, mas não diz como isso é possível. Como se pode afirmar, apoditicamente (sem margem para dúvidas), que o mundo exterior existe e que ele transmite conhecimento? Por exemplo, como a ciência positiva seria capaz de refutar a tese de que vivemos em um mundo tal qual o do filme Matrix ${ }^{2}$ ? Ou que isto que se experiencia agora é apenas um sonho e que, ao acordar, se perceberá que nunca existiu? A ciência não é capaz de refutar essas hipóteses porque elas não podem ser postas à experimentação. Assim sendo, ela precisa dogmatizar a questão e colocar como premissa não problematizada a existência do mundo exterior.

Deste modo, o movimento fenomenológico também surge como crítica à ciência positiva tida como método supremo de conhecimento. Para ele, é necessário criar um conhecimento que questione os seus próprios pressupostos e se sustente em algo que não pode ser refutado ou posto em dúvida. A função da filosofia, nesse contexto, é encontrar esse conhecimento e, dessa forma, fundamentar todos os demais ramos do saber (RIBEIRO JÚNIOR, 2003, p. 27).

Esses pressupostos desenvolveram-se em diversos aspectos da abordagem fenomenológica, cujo núcleo central apresentado permite uma orientação geral sobre o posicionamento de Edmund Husserl. A partir deles, é possível explicar outros aspectos da fenomenologia que influenciaram o estudo da ciência jurídica, principalmente no que tange à noção de essências imutáveis e atemporais, que será o principal objeto de crítica aqui formulado.

\footnotetext{
${ }^{2}$ Matrix é um filme de ficção lançado em 1999, escrito e dirigido pelos irmãos Wachowski. O enredo se passa em um futuro pouco distante em que um hacker de computadores descobre que a vida na Terra, tal qual se concebe, é apenas um programa de computador chamado Matrix. Para mais informações, acessar <https://goo.gl/q1YWfZ>.
} 


\section{AS INFLUÊNCIAS DA FENOMENOLOGIA NO ESTUDO DA CIÊNCIA JURÍDICA}

\subsection{A NECESSIDADE DE REFLEXÃO ACERCA DOS FUNDAMENTOS E A LEGIMITAÇÃO AXIOLÓGICA DOS DIREITOS FUNDAMENTAIS}

Assim como a fenomenologia criticou o positivismo científico, uma série de teóricos tiverem o positivismo jurídico como alvo de crítica, principalmente em relação a estes dois aspectos fundamentais do positivismo jurídico: o Direito apenas como Direito positivo e o cientista do Direito como aquele que descreve os sentidos que um enunciado normativo pode ganhar, independentemente de valores ou ideais políticos.

Como as contribuições da fenomenologia afetaram as respostas dadas as essas questões será objeto de análise a seguir.

A primeira questão a ser discutida é referente ao objeto de análise da ciência jurídica, ou seja, o conceito de Direito. Hans Kelsen atribui apenas às normas positivas o caráter da juridicidade, o que afastou da ciência jurídica as questões axiológicas. O objeto do Direito passou a ser apenas as normas estatais (KELSEN, 2006, p. 20).

Como consequência, na busca por desenvolver essas regras e demais institutos em que se baseia, como “direito subjetivo”, “dever jurídico”, etc., o positivismo jurídico caiu no mesmo problema que o filosófico: perdeu-se nas leis abstratas e gerais e esqueceu-se do mundo vivido, do papel que o Direito possui em uma sociedade concreta. Como aponta Bussinguer (2012, p. 66-67): "Tendo cristalizado uma forma de ser fundamentalmente normativista e positivista, o Direito deixou de olhar o mundo da vida e dos homens para os quais existe, que lhe dão sentido e que, portanto, devem estar no centro de suas atenções e destinatários maiores de sua prática”.

Nesse contexto, a fenomenologia tem influenciado a crítica ao positivismo jurídico na medida em que busca recolocar a questão do fundamento da ordem jurídica dentro de um contexto maior, e não apenas no procedimento estatal (GUIMARÃES, 2007, p. 59).

Ao dar foco ao “mundo da vida”, a partir das relações mesmas que se dão na sociedade, e não a partir de imperativos condicionais abstratos, a recolocação do problema dos fundamentos do Direito ganhou espaço na medida em que o fortalecimento dos direitos humanos também impulsionou a busca por um núcleo material que fosse além das regras, ampliando o recorte positivista para abrir espaço para a análise jurídica de valores e princípios. Assim, desloca-se o debate jurídico, do procedimento institucionalizado e das normas positivas para a busca pela essência do Direito.

É nesse sentido que Guimarães (2007, p. 69-70) escreve: 
O Direito positivo prescreve regras, cujos comandos formam a estrutura jurídica de um País. [...] Quem formula as regras normativas e a partir de que pressuposto? As regras normativas incorporam o Direito? Quais as relações existentes entre Direito e a Lei? Eis a questão de uma eidética do Direito. Buscar as essências como substratos de todo o formalismo jurídico.

Assim, no momento que o ser humano é tido como o fundamento do ordenamento jurídico, implica-se o questionamento da velha distinção positivista entre ser e dever ser, segundo a qual seria impossível retirar um conteúdo normativo de um fato da realidade (GUIMARÃES, 2007, p. 59-60).

Como demonstra, em seu preâmbulo, a Declaração Universal dos Direitos Humanos (ORGANIZAÇÃO DAS NAÇÕES UNIDAS, 2009), a dignidade humana e os valores dela extraídos não são atribuídos pelo Estado, mas reconhecidos, visto que “inerentes a todos os membros da família humana”. Assim, deriva-se a normatividade da ordem jurídica (dever ser) da própria natureza humana enquanto tal (ser).

Para a fenomenologia, tanto o ser quanto o dever ser articulam-se no horizonte da própria natureza, "da estrutura normativa produzida pela consciência humana intencionada à garantia de realização da obrigatoriedade da coexistência” (GUIMARÃES, 2007, p. 62). Só na medida em que a própria natureza intenciona essa obrigatoriedade, deduz-se a necessidade do Estado. Por isso, entende-se que "a cultura [o espírito] é fruto da natureza porque sobre ela [a natureza] foram edificados os alicerces da civilização” (GUIMARÃES, 2007, p. 64).

Uma vez feita a crítica quanto à redução do conceito de Direito às regras positivadas, a fenomenologia passa a ser útil como corrente de pensamento que propõe analisar a essência, o fundamento dos direitos humanos, demonstrando suas categorias fundamentais. Por isso, mais do que observar os direitos humanos como normas positivadas em declarações e constituições, é necessário enxergá-los a partir da pessoa humana e buscar descrever suas essências. Isso significa dizer que as leis apenas encobrem o ser dos direitos humanos; são apenas entes (GUIMARÃES, 2007, p. 69-70).

O emprego do termo "ente” foi proposital e visa permitir um esclarecimento acerca da fenomenologia de Husserl e a de Heidegger. Em termos husserlianos mais precisos, o texto legal seria apenas um elemento acessório (transcendente), não essencial. Por isso, ele seria posto em suspensão pelo processo de redução fenomenológica, sendo indiferente para a busca da essência. Já em Heidegger, a redução fenomenológica é entendida como uma diferenciação ontológica, em que a manifestação textual da norma é apenas um ente, uma forma de manifestação do ser, não o representando em sua completude.

$\mathrm{Na}$ mesma oportunidade, é suficiente justificar a razão pela qual não foi tratada especificamente a questão do termo mundo vivido, muito utilizado na fenomenologia e criado por Husserl sob a designação alemã lebenswelt. Na redução fenomenológica de Husserl, esse mundo 
vivido é posto em suspensão e o puro ver é entendido como universalidade, não enquanto existência concreta (STEIN, 2004, p. 26). Heidegger, ao desenvolver sua própria teoria fenomenológica, considerou que “a redução transcendental excluía algo que não podia ser excluído” (STEIN, 2004, p. 27).

Essa objeção é a base da crítica heideggeriana à fenomenologia tratada por este texto, e foi a partir dela que Heidegger desenvolveu a expressão “ser-no-mundo”. Em suma, enquanto o sentido das coisas se dá, em Husserl, na universalidade do interior da consciência - portanto, de um eu transcendental, ignorando a influência do mundo vivido para essa construção de sentido -, Heidegger considera exatamente o oposto, sustentando que o sentido das coisas vem do mundo (STEIN, 2004, p. 40). Por essa razão, a crítica realizada neste texto não alcança a fenomenologia heideggeriana ou a tese do sentido do ser a partir do mundo vivido.

Feitas essas ressalvas, observa-se que a preocupação fenomenológica de Husserl com as essências auxiliou o estudo da ciência jurídica ante o reducionismo positivista. Na medida em que a fenomenologia traz as bases filosóficas para se analisar o conteúdo das proposições valorativas, ela também permite que a ciência jurídica amplie seu objeto de estudo.

Nada obstante, será visto no decorrer deste trabalho que a virtude que permitiu a ampliação do conceito de Direito, a busca pelo seu caráter essencial além do Direito positivo, contribuição dada por Husserl em seu objetivo de alcançar os princípios genéricos absolutos, pode vir a constituir um obstáculo ao estudo do Direito. Será necessário analisar que a ideia de um conhecimento invariável, de essência, que, apesar de já questionado por alguns fenomenólogos posteriores a Husserl, continua a ter influência nos estudos de Teoria Geral do Direito, pode não ser compatível com as noções que se tem de Estado Democrático de Direito. Ou seja, a busca pela essência como sentido de imutabilidade pode gerar incompatibilidade com a noção de Estado Democrático de Direito, entendido como regime político apto a captar todo o dinamismo histórico que uma sociedade possui no decorrer do tempo.

\subsection{O ABALO À TEORIA PREDICATIVA EM RELAÇÃO ÀS CONDIÇÕES DE POSSIBILIDADE DE CONHECIMENTO DO HERMENEUTA NA CONSTRUÇÃO DE SENTIDO DA RESPOSTA CORRETA}

Além do conceito de Direito, a fenomenologia também influenciou na renovação dos métodos de interpretação dos dados jurídicos. Em consonância com o objeto de análise que possuía, o positivismo jurídico tornou o processo de interpretação do Direito um processo científico de explicitação de sentido. Desse modo, caberia ao pesquisador do Direito descrever todos os possíveis 
sentidos que o enunciado positivo poderia oferecer na forma linguística do princípio da imputação (se A, então B).

Como reconhece Kelsen, usualmente esse processo não será capaz de determinar um único sentido para o enunciado. Isso por causa da plurissignificação da maioria das normas jurídicas (KELSEN, 2006, p. 396), plurissignificação essa que é concebida pelo positivismo por se basear na estrutura científica da observação do texto normativo e pretender não extrair qualquer significado que não esteja presente nele. Assim, o ato de conhecimento, que é a observação e interpretação do sentido da norma para o positivista, é um ato sempre impreciso, porque tem como fonte de conhecimento a própria linguagem, com suas aporias e ambiguidades.

Esse aspecto do positivismo jurídico foi tratado de forma explícita por Hart (2001, p. 139), que sustenta que

em todos os campos de experiência, e não só no das regras, há um limite, inerente à natureza da linguagem, quanto à orientação que a linguagem geral pode oferecer. [...] Os cânones de interpretação não podem eliminar estas incertezas, embora possam diminuí-las; porque estes cânones são eles próprios regras gerais sobre o uso da linguagem e utilizam termos gerais que, eles próprios, exigem interpretação.

Isso não é um problema para a fenomenologia. Na medida em que o objeto de análise do Direito é ampliado para abarcar as questões valorativas, o pesquisador do Direito que assume uma postura fenomenológica passa a poder se debruçar sobre o sentido essencial que pode ser intuído do texto.

Desse modo, Husserl percebeu que a ciência positiva da descrição sempre demanda um conhecimento que é prévio à própria descrição. Um conhecimento que pode ser pensado pelo seguinte exemplo: a ciência natural, baseada apenas em descrições dos fatos, ao se perguntar o que é um cálice responderá tal qual um conceito de dicionário, qual seja, um copo pequeno com pé. Sob essa perspectiva, o objeto foi observado e o sujeito simplesmente mencionou as características que pertencem ao objeto. No entanto, surgem algumas lacunas nessa análise. Quando se pergunta o que é um cálice, como saber quais dos objetos da natureza que devem ser descritos? Para se saber quais são os objetos que devem ser analisados, não é necessário um conhecimento prévio do que é cálice? ${ }^{3}$

Seguindo as premissas de fundo da teoria científica, pensa-se: um certo dia alguém observou um objeto outrora desconhecido e resolveu chamá-lo de cálice. Depois de ter assim convencionado, mostrou o objeto para outros indivíduos e disse que se chamava cálice. Descrevendo o que observava, considerou que cálice era um objeto de aproximadamente $15 \mathrm{~cm}$ de altura, feito de prata e que possuía

\footnotetext{
${ }^{3}$ A utilização do cálice é exemplo recorrente para a ilustração da percepção que a abordagem filosófica possui em relação ao ente e sua individualização do mundo e está, inclusive, apresentado em uma das obras de Martin Heidegger (2002).
} 
duas cavidades, uma maior e mais ovalada e outra menor e mais estreita. Observou que ambas as cavidades eram unidas e permitiam que o objeto como um todo se mantivesse de pé quando apoiado por qualquer uma das cavidades e que rolasse, caso posto horizontalmente. Esse observador considerou que seria um belo objeto para beber líquidos, principalmente com sua cavidade maior.

Em outro dia, observou um outro objeto. Esse era de ouro, media $25 \mathrm{~cm}$ e também possuía duas cavidades unidas. Ele era diferente do objeto anterior, mas possuía semelhanças, razão pela qual considerou que também se tratava de um cálice. Como os dois eram cálices, o tamanho e a cor já eram indiferentes para o conceito de cálice. Logo, o cálice passou a ser identificado pela sua forma: duas cavidades unidas, capazes de se sustentar verticalmente, mas que tornam possível ao objeto rolar na horizontal.

No terceiro dia esse observador viu outro objeto. Esse possuía uns $40 \mathrm{~cm}$, era de cobre e tinha duas cavidades unidas; era capaz de se equilibrar verticalmente e rolava quando posto na horizontal. Era diferente dos dois anteriores, mas se enquadrava no conceito atribuído a cálice. Nada obstante, considerou que eram objetos diferentes. Como uma cavidade era bem menor, considerou que ele seria apropriado para colocar velas. Ele denominou esse objeto de castiçal.

Pensando no problema da insuficiência do conceito anteriormente dado a cálice, resolveu adicionar nele a utilidade do objeto. Assim, tanto cálice quanto castiçal seriam duas cavidades unidas, capazes de se sustentar verticalmente, mas que rolam na horizontal, sendo que cálice serviria para beber líquidos e castiçal para pôr velas.

Uma segunda pessoa, um clérigo, possuía conhecimento de castiçal, mas nunca tinha observado ou tido notícia de um cálice. Ele estava com um problema na paróquia, porque as velas utilizadas para clarear a igreja à noite gastavam-se muito rapidamente, de forma que pediu que fosse feita uma vela mais grossa, que durasse mais tempo - uma vela de sete dias. Isso gerou um problema, porque a vela não cabia nos castiçais.

Um dia, por acaso, deparou-se com o outro objeto narrado nesse exemplo. Observou sua forma e pensou ser adequado para pôr a vela que havia mandado fazer. Assim, considerou que o objeto era um castiçal para velas grossas.

Enfim, com o exemplo narrado surgem duas questões que a premissa empírica não consegue explicar: primeiro, como é possível ao intelecto humano identificar objetos semelhantes e considerálos iguais quando todos os objetos e eventos do mundo são sempre únicos? Segundo, quais são os critérios para se predicar um determinado objeto a fim de que se possa criar um conceito abstrato para todos os objetos semelhantes? A forma? A utilidade? O segundo objeto é um cálice no qual foi posta uma vela ou um castiçal para velas grossas? 
Com isso, o movimento fenomenológico tentou sustentar que o conhecimento humano não se funda apenas na experiência e memorização do passado que, sendo aplicado em eventos atuais, permite o reconhecimento das coisas e produção do conhecimento. O movimento fenomenológico defende que já existe um conhecimento anterior à experiência, conhecimento esse que é a própria condição de possibilidade para o conhecimento empírico.

Esse conhecimento fenomenológico, por sua vez, não tem como objeto de pesquisa a ideia de um “objeto empiricamente observável” (como na ciência positiva), mas volta-se para o estudo dos fenômenos. “O fenômeno não é, portanto, um objeto que 'está aí diante dos olhos’, mas é sobretudo algo que se mostra e se dá à experiência desse 'ver’”' (BUSSINGUER, 1991, p. 18).

Quando o exemplo é transportado para o estudo do Direito, descobre-se que a fenomenologia, na medida em que permitiu a ampliação do objeto da ciência jurídica, também retirou toda a prioridade que o enunciado normativo possuía. Não é necessário se preocupar com a ambiguidade e vagueza dos termos linguísticos quando eles não são a fonte da norma jurídica, mas apenas um evento que inicia o trabalho do pesquisador. Cabe ao jurista fenomenológico descobrir o elemento invariante que pode ser intuído do enunciado.

Assim, o objeto privilegiado da fenomenologia são as fontes do conhecimento, "os dados absolutos genéricos, que constituem as medidas fundamentais e universais pelas quais há de medir todo o sentido e, em seguida, também o Direito, do pensar confuso, e resolver todos os enigmas que ele põe na sua objectalidade” (HUSSERL, 1989, p. 84), tudo isso visando permitir uma transição segura de um conhecimento da esfera da interioridade (imanência) para a esfera de exterioridade (transcendência) (CUNHA, 2013, p. 80).

Para encontrar esse dado seguro, parte-se da premissa de que é proibido à fenomenologia pressupor algo como “previamente dado”. Por isso, em Husserl (1989, p. 53), tudo ganha a característica da questionabilidade. Nesse sentido, a base para um conhecimento seguro, tal qual deseja a fenomenologia, precisa ser um conhecimento "que devemos reconhecer como absolutamente dado e indubitável, na medida em que está dado justamente de um modo tal que nele existe plena claridade, a partir da qual toda a pergunta encontre e deva encontrar a sua resposta imediata” (HUSSERL, 1989, p. 54).

Essa busca já foi realizada antes na história da filosofia, como em Descartes (CAPALBO, 2008, p. 41). Lévinas (1997, p. 11-12) explica, nesse sentido, que

Husserl inquieta-se com as bases inconstantes em que assenta o edifício do saber. A necessidade de fundar as ciências numa doutrina universal e absoluta liga-o a Descartes. A 
sua filosofia aspirará a conduzir-nos às primeiras evidências, sem as quais não seria digna do seu nome.

Ao adequá-la aos problemas aqui trazidos, a busca de Descartes sugere bons elementos para a premissa que a fenomenologia procura. Ao se perguntar sobre a essência do conhecimento, o próprio conhecimento, em suas configurações intelectuais, surge como ente dado. Sob o ponto de vista do evento singular, ensina Husserl (1989, p. 54-55) que essas configurações podem significar juízos, raciocínios ou representações, de forma que, no momento em que se reflete sobre elas, cria-se uma situação de percepção pura.

Em suma, “toda a vivência intelectiva e toda a vivência em geral, ao ser levada a cabo, pode fazer-se objeto de um puro ver e captar e, neste ver, é um dado absoluto. Está dada como um ente absoluto, como um isto-aqui (Dies-da), de cuja existência não tem sentido duvidar” (HUSSERL, 1989, p. 55-56). Disso se alcança uma “esfera de dados absolutos”, um conhecimento propriamente imanente e elemento necessário para se alcançar uma crítica do conhecimento tal qual ambicionada pela fenomenologia (HUSSERL, 1989, p. 56, 59).

Assim, fica clara a contraposição entre o positivismo e a fenomenologia. A fenomenologia acredita que o positivismo resolveu adotar como objeto de análise aqueles dados imprecisos, obscuros, cuja variabilidade impede qualquer conhecimento seguro. Essa mudança de perspectiva permite entender por que Kelsen, buscando fazer uma ciência do Direito, precisa lidar com as plurissignificações do texto legal.

Por conseguinte, para alcançar os elementos invariáveis que podem ser observados do texto legal, ou seja, as essências, precisa-se de uma intuição eidética ${ }^{4}$, uma “visão do sentido ideal que [se atribuiu] ao fato materialmente percebido e que nos permite identificá-lo” (DARTIGUES, 2008, p. 20).

Essa identificação pode ser alcançada por meio da variação eidética, processo que visa retirar do fato observado tudo aquilo que não é essencial. Não se trata de “comparar ou concluir, mas de reduzir, isto é, de purificar o fenômeno de tudo o que comporta de inessencial, de 'fático', para fazer aparecer o que lhe é essencial” (DARTIGUES, 2008, p. 32).

Esse processo “consiste em imaginar, a propósito de um objeto tomado por modelo, todas as variações que ele é suscetível de sofrer” (DARTIGUES, 2008, p. 33). Assim, em vez de se ater ao

\footnotetext{
${ }^{4}$ Ainda sobre a intuição eidética: “A visão das essências é uma intuição, isto é, um ato de conhecimento direto, sem intermediários, que nos põe em presença, num face a face ao objeto 'em pessoa'. Ele [Husserl] chamará de intuição doadora a este ver que constitui seus objetos” (CAPALBO, 1987, p. 17).
} 
estudo da ambiguidade e vagueza do dado transcendente que é o enunciado jurídico, o pesquisador deve buscar a essência daquilo que observa, como a justiça, a liberdade, enfim, a norma para o caso.

Com isso, o pesquisador é capaz de uma redução fenomenológica, “uma operação pela qual o espírito suspende a validade da tese natural da existência para estudar o seu sentido no pensamento que a constituiu e que, ele próprio, já não é uma parte do mundo, mas anterior ao mundo” (LÉVINAS, 1997, p. 48). Assim sendo, o método fenomenológico proíbe todo o juízo que verse sobre a existência espaço-temporal (CAPALBO, 2008, p. 42-43).

Isso tem levado a uma outra influência da fenomenologia no estudo do Direito. Na medida em que aspectos considerados ambíguos para o positivismo podem ser elementos de análises objetivas para a fenomenologia, a busca pela resposta correta passa a ser uma possibilidade para o jurista fenomenológico, e a discricionariedade judicial, um desafio que pode ser superado.

Influenciada pelos pressupostos da fenomenologia, a abordagem de Lenio Streck (2008) pode servir de ilustração para demonstrar essas contribuições advindas da filosofia fenomenológica.

No trecho em que critica uma teoria predicativa da norma jurídica, Streck (2008, p. 310) diz que “a resposta (correta) ultrapassa a questão da ‘analítica da proposição’; ela não estará na proposição, mas, sim, em uma dimensão anterior à dimensão proposicional”. E continua:

trata-se da "resposta”, que exsurge da síntese hermenêutica, enquanto descrição fenomenológica, e que será o ponto de estofo em que se manifesta a coisa mesma (die Sache selbst). Aliás, em seu repto contra relativismos e irracionalidades, Gadamer diz: para a hermenêutica, o relativismo não deve ser refutado, deve ser destruído! (STRECK, 2008, p. 319).

Essas passagens ajudam a formar a imagem daquilo que os juristas têm trazido junto com o desenvolvimento da fenomenologia: a noção de que o sujeito participa do processo de significação que gera a norma jurídica, tanto quanto ou mais que o próprio enunciado jurídico.

Assim, podemos sintetizar as principais contribuições que a fenomenologia tem dado ao estudo da ciência jurídica a partir de seu objetivo de construir um método capaz de lidar com questões para além do texto legal e, com isso, conseguir resolver a questão da vagueza e ambiguidade com que precisam conviver os positivistas. 


\section{OBSTÁCUlos DA METODOLOGIA FENOMENOLÓGICA PARA A CIÊNCIA JURÍDICA}

Apresentadas as influências e contribuições que os pressupostos fenomenológicos têm trazido para a ciência jurídica, é preciso pensar acerca dos problemas que advêm dessa abordagem.

Em conformidade com o objetivo dessa pesquisa, que é demonstrar os obstáculos que dificultam a utilização do método fenomenológico na ciência jurídica, serão apresentados os empecilhos da fenomenologia no que trata da verificabilidade e da transparência dos seus resultados, bem como a incompatibilidade que os pressupostos fenomenológicos possuem com uma perspectiva dinâmica de democracia.

\subsection{A VERIFICABILIDADE E A TRANSPARÊNCIA DOS RESULTADOS FENOMENOLÓGICOS ANTE A NECESSIDADE DE CERTEZA DO DIREITO}

Apesar de todas as críticas acima elencadas, uma das contribuições que a ciência positiva deu à metodologia foi o postulado da verificabilidade. Conforme Humberto Eco (2007, p. 54-55), a pesquisa científica tem como um dos pressupostos o fornecimento de elementos capazes de confirmar ou rejeitar as hipóteses que são apresentadas.

Nas ciências naturais isso deu-se com base na capacidade de um mesmo experimento, quando repetido nas mesmas condições, sempre gerar um mesmo resultado. Já na ciência jurídica isso advém da clareza e transparência das etapas de pesquisa.

Quando o pesquisador do Direito pretende buscar o sentido de determinada norma, seja encontrando os múltiplos sentidos que advêm de seu enunciado, seja demonstrando a essência do Direito ou instituto em discussão, é necessário que ele demonstre como chegou às próprias conclusões.

Esse problema também está presente na atividade jurisdicional, principalmente quando se observa o dever de fundamentação do magistrado, na forma do art. 93, IX, da Constituição da República (BRASIL, 1988). É preciso que tanto os indivíduos, partes do processo, quanto a coletividade reconheçam a decisão jurisdicional como legítima e não como uma arbitrariedade.

Esse é um primeiro obstáculo sobre o qual a fenomenologia precisa se debruçar. Por mais que os métodos fenomenológicos tivessem como objetivo inicial um rigor científico, sua aplicação, conforme originariamente pensada por Husserl, é difícil de ser encontrada na prática. 
Por exemplo, a tese da redução fenomenológica e a da variação eidética, como já assinalado, representam um processo de busca intuitiva pelos elementos invariáveis do conhecimento. A questão que surge daí é que o processo intuitivo não pode ser posto em linguagem metodologizada.

João Maurício Adeodato (2013, p. 117), um crítico da fenomenologia, ilustra o método fenomenológico com o exemplo do vegetal:

Tome-se um exemplo simples: o conceito de "vegetal". É preciso investigar seu sentido extrínseco. Esse não se baseia certamente no tamanho, na cor ou no número de folhas do objeto. Estes são acidentes. O fato de ser vivo e privado de autolocomoção, por exemplo, pode ajudar; ou então o fato de possuir clorofila e realizar a fotossíntese. Se se admite que há vegetais que não possuem clorofila e que não realizam a fotossíntese, o método fenomenológico tem que procurar outro caminho.

Entendido dessa forma, o método fenomenológico tem dois problemas. Primeiro, como bem atenta Adeodato, "a dificuldade prossegue quando se verifica que cada um dos conceitos utilizados na definição de outro conceito precisa também ser submetido à redução fenomenológica” (ADEODATO, 2013, p. 117). Isso faz com que a atividade fenomenológica se torne praticamente impossível de ser realizada pelo jurista e, até mesmo, pelo filósofo.

Ademais, há uma segunda questão. Capalbo (1987, p. 29) busca demonstrar que existe diferença entre definir e descrever para a fenomenologia. Segundo ela, Husserl

quer liberar o nosso olhar para a análise do vivido, das experiências puramente vivenciais. Esse vivido não poderá ser definido, mas apenas descrito. O nosso olhar interior, isto é, a nossa consciência liberada se caracteriza por ser intencional, como consciência voltada para alguma coisa, com consciência de algo.

Com isso, a fenomenologia reconhece que, para ir às coisas mesmas, ela não pode se prender ao pensamento linguisticamente formulado, pois a própria linguagem é um aspecto transcendente, não essencial do pensamento. Como aponta Lévinas (1997, p. 140, grifo do autor),

Husserl reconhece essa imperfeição do desígnio significativo no equívoco que desliza inevitavelmente para o pensamento verbal. O equívoco, defeito aparentemente menor e que parece poder esconjurar-se com um pouco de clareza no pensamento - estabelece logo como inevitável ou como essencial ao pensamento que se limita às palavras.

O argumento de Husserl acerca de um conhecimento pré-predicativo foi uma contribuição incrivelmente bem elaborada e cujos pressupostos os positivistas dificilmente conseguiram contrapor. Ora, para definir o que é “vegetal” é preciso saber quais elementos irão compor o conjunto de análise. Nada obstante, esse conhecimento pré-predicativo não pode ser transformado em linguagem, sob o risco de se "predicalizar”. 
Quando explicitado em termos linguísticos o conhecimento que foi intuído eideticamente, o pesquisador adiciona a essa intuição uma série de características transcendentes, ou seja, surge o obstáculo de um conhecimento seguro, mas incomunicável linguisticamente.

Esse obstáculo gera graves consequências para o Direito. A ampliação do objeto do Direito para o estudo dos valores e dos direitos fundamentais tem gerado uma série de teorias, como é o caso da teoria do "conteúdo essencial dos direitos fundamentais".

No julgamento da ADI 3.540-1, que tratou da inconstitucionalidade de um artigo do Código Florestal, observa-se que o relator, Min. Celso de Mello, na fundamentação de seu voto, ao reconhecer a questão axiológica acerca dos direitos fundamentais, em especial o direito fundamental ao meio ambiente, também reconheceu que, “em função de determinado contexto e sob uma perspectiva axiológica concreta”, é necessário ponderar entre os valores que concorrem para o caso, para que com isso “a utilização do método da ponderação de bens e interesses não importe em esvaziamento do conteúdo essencial dos direitos fundamentais” (BRASIL, 2005, p. 566-567).

O fundamento concilia-se com as contribuições fenomenológicas apresentadas, amplia o conceito de Direito para além do enunciado jurídico e reconhece que existe uma essência invariável para os direitos fundamentais que não pode ser infringida.

Saber se houve ou não violação a essa essência implica saber qual é a essência. Conforme a fenomenologia, esse processo realmente pode ser intuído eideticamente, mas ele não pode ser, conforme defendido, predicalizado. Ainda assim, se for predicalizado, posto em uma sentença, por exemplo, não é possível controlar esse raciocínio, ou seja, demonstrar por quais etapas o raciocínio realizado pelo julgador passou para alcançar as conclusões de essência.

Estar-se-ia, então, diante de um obstáculo concreto do método fenomenológico. O único controle de verificabilidade possível dos resultados alcançados por esse método seria a concordância, também intuitiva, dos demais indivíduos, transformando-se numa tarefa realmente árdua diferenciar intuição eidética de capacidade retórica ou congregação de interesses.

Quando se é deparado com uma alegação dessas, o fenomenólogo poderia contra-argumentar que sempre poderá haver maus fenomenólogos, que não realizam corretamente o processo de redução fenomenológica e, por isso, acabam confundindo a essência do fenômeno com outros elementos variáveis, transcendentes (DARTIGUES, 2008, p. 37).

Apesar de o argumento da não utilização correta do método representar importante reflexão e ponderação a ser feita, ele não é suficiente para superar toda a crítica realizada, porque, ao que parece, a capacidade de se diferenciar os bons e os maus fenomenólogos continua sendo um importante desafio para a fenomenologia. 


\subsection{ESSÊNCIA E MUTABILIDADE NO MÉTODO FENOMENOLÓGICO}

Para Husserl, é a “estrutura invariante cuja presença [é] permanente [que] define a essência do objeto” (CAPALBO, 1987, p. 15). Entretanto, essa essência também não é, como em Platão, parte de um mundo inteligível que é a forma de todo o mundo sensível. Essas essências não são metafísicas, mas estão presentes na consciência intencional que é característica de um “eu” transcendental (DARTIGUES, 2008, p. 21).

A noção das essências dessa forma é parte do projeto de Husserl em tentar criar uma filosofia cientificamente segura. No entanto, essa noção de essência gera um resultado do qual nem sempre os pesquisadores do Direito apercebem-se. Ela implica um imobilismo de sentido. Afinal, não se pode supor que um elemento invariável possa variar, seja em razão do lugar, seja em razão do tempo.

Por conta disso, a fenomenologia, tal qual pensada por Husserl, envolveria uma intuição do sentido do texto em que todos os fatores sociais, históricos e culturais fossem reduzidos. O sentido dos direitos fundamentais e demais enunciados se cristalizariam, dessa forma, no sentido transcendental que o método fenomenológico pretende encontrar.

Essa premissa entra em contradição com uma prática que tem ganhado muita relevância da ciência jurídica: a mutação constitucional. Segundo Adriano Pedra (2010, p. 9), mutação constitucional é um “processo informal que cuida da alteração da Constituição. Na mutação, a norma constitucional modifica-se apesar da permanência de seu texto, pressupondo a não identificação entre texto e norma”5.

Tal processo pressupõe, dessa forma, que o sentido do texto é tão variável quanto qualquer outro dado transcendente, mesmo que só podendo ser observado em uma maior escala de tempo. Essa abertura dinâmica da Constituição tem justificado algumas decisões que alteraram substancialmente o sentido que se atribuía ao enunciado jurídico, como é o caso da decisão Brown vs. Board of Education, que acabou com a segregação racial nas escolas públicas norte-americanas, ou do caso das decisões da ADI 4277 e da ADPF $132^{6}$, que reconheceram a união estável entre pessoas do mesmo sexo como entidade familiar.

É preciso ressalvar ainda que, para as correntes que defendem a mutação constitucional, como é o caso de Friedrich Müller (2008), a crítica de Husserl é pertinente. Os dados transcendentes

\footnotetext{
${ }^{5}$ Outro exemplo de perspectiva dinâmica da sociedade e da concepção de democracia foi demonstrado em outro trabalho, em que se pesquisou acerca da história das ideias jurídicas de Rui Barbosa na campanha eleitoral de 1919 (LARANJA, 2015).

${ }^{6}$ A ADI 4277 e a ADPF 132 foram julgadas conjuntamente pelo STF, cuja decisão de equiparação das uniões homoafetiva às uniões estáveis heterossexuais foi por unanimidade (HAIDAR, 2011).
} 
são sempre inseguros e irrepetíveis, e o conhecimento deles advindo sempre perecerá. Nada obstante, Müller considera que, ainda que passageiros, esses dados são os que realmente importam para a construção do sentido da norma, de forma que além de aproveitar os dados linguísticos, tal qual o positivismo, ainda se somam à norma os dados da realidade concreta ${ }^{7}$.

Em contrapartida, um fenomenólogo poderia explicar essas variações com o argumento de que se trataria de, por exemplo, uma correção da ideia de um valor (igualdade, no caso do exemplo), cuja essência só foi adequadamente intuída com essas decisões. Assim, as mudanças de sentido seriam, na verdade, uma percepção de um erro passado e que foi, no momento da decisão, definitivamente corrigido.

A diferença de postura, portanto, entre um fenomenólogo e um autor de outra corrente filosófica, como é o caso de Friedrich Müller, por exemplo, geram sentidos diferentes para o Estado Democrático de Direito.

Para os primeiros, o valor é algo que precisa ser adequadamente intuído e sua intuição já o demonstra de forma acabada, invariável. Assim, caberia aos operadores do Direito reconhecer as essências dos valores (ou os núcleos essenciais dos direitos fundamentais) que formam o texto constitucional. A democracia materialmente realizada é, portanto, um regime de governo que reconhece as essências invariáveis dos valores que a formam, como a liberdade e a igualdade.

Por outro lado, autores como Friedrich Müller seguiram o caminho oposto. Eles entendem a democracia a partir de premissas sempre inacabadas, cuja realidade sempre irrepetível deve ser levada em consideração no momento de aferição do sentido dos enunciados jurídicos, bem como dos direitos fundamentais, porque estes sentidos são sempre variáveis.

Se ao pesquisador do Direito cabe a busca pelos valores invariantes que conformam a noção de democracia ou, ao contrário, a suposição de que essas ideias são sempre relativas ao momento histórico de determinada sociedade, não é possível obter respostas sem se retomar um debate que há muito tem se travado entre historicistas e axiologistas. Para os fins deste artigo, no caso, basta reconhecer os obstáculos que a fenomenologia apresenta pela incompatibilidade de seus pressupostos com um ideal socialmente dinâmico de democracia.

\footnotetext{
${ }^{7}$ Sobre a teoria de Friedrich Müller: "Nesse sentido, para a construção da norma jurídica com base no caso jurídico e nos textos normativos, o jurista necessita tanto de dados linguísticos como de dados reais. Esses elementos constituem o programa normativo (dados da linguagem) e o âmbito normativo (dados reais). Assim, do ponto de vista da teoria da norma, o programa normativo e o âmbito normativo são apenas elementos integrantes da norma” (PEDRA, 2013, p. 56, grifos do autor).
} 


\section{CONCLUSÃO}

O desenvolvimento do movimento fenomenológico e as críticas que ele realizou à “absolutização” do conhecimento científico trouxeram grandes contribuições para a ciência jurídica. A fenomenologia auxiliou na reflexão do problema da indeterminação dos textos e na abertura do conceito de Direito para os elementos axiológicos.

A proposta defendida por Husserl, de uma "filosofia cientificamente rigorosa", visava à ampliação dos limites das ciências positivas sem que, com isso, se perdesse seu rigor e segurança. Todavia, a relação entre a amplitude do conhecimento, combinada com um alto grau de verificabilidade desse conhecimento, ainda é um obstáculo a ser enfrentado pela fenomenologia e demais correntes metodológicas.

O positivismo buscou um conhecimento fortemente seguro, precisando, para isso, restringir seu objeto de estudo a elementos demasiadamente específicos, bem como ignorar qualquer conhecimento sobre valores ou essências.

Ao contrário, a fenomenologia tentou ultrapassar esses limites do positivismo, mas ainda apresenta uma série de obstáculos que desafiam sua utilização pela ciência jurídica, principalmente no que se refere à transparência de seu método e verificabilidade dos seus resultados.

Além disso, o método fenomenológico traz um obstáculo em relação à mutabilidade histórica dos sentidos atribuídos aos valores que guiam os textos jurídicos, já que as premissas de Edmund Husserl consideram esses valores como elementos invariáveis.

Outras concorrentes da fenomenologia, como a teoria apresentada por Martin Heidegger (2013), reconhecem e abarcam essa multiplicidade e abertura observadas. No entanto, é duvidoso acreditar que elas se mantêm na mesma proposta da fenomenologia tal qual pensada originalmente por Husserl.

Enfim, a fenomenologia de Husserl é uma teoria propriamente filosófica. Esse autor não tinha como objeto de estudo específico a ciência jurídica, bem como não pretendeu criar uma teoria específica para o Direito. Nada obstante, na medida em que almejou a busca pelo fundamento último que orienta a relação entre o homem e o conhecimento, é inegável que suas conclusões interferem em todas as demais áreas do conhecimento.

Assim, questionar sobre como essas conclusões servem de premissas, ainda que inconscientes, para fundamentar determinados discursos como o do "núcleo essencial dos direitos fundamentais” é importante para resguardar a coerência que o pesquisador do Direito deve possuir na observação dos seus objetos de pesquisa. 
Adotar o método fenomenológico de Edmund Husserl pode ser um “caminho” importante para buscar uma fundamentação material para a democracia e para os direitos fundamentais, mas também impõe, ao pesquisador, ter que enfrentar, como obstáculos, fenômenos de mutabilidade que têm marcado algumas das principais concepções do direito constitucional contemporâneo.

\section{REFERÊNCIAS}

ABBAGNANO, Nicola. Dicionário de Filosofia. São Paulo: Martins Fontes, 2007.

ADEODATO, João Maurício. Filosofia do direito: uma crítica à verdade na ética e na ciência. 5. ed. São Paulo: Saraiva, 2013.

BRASIL. Constituição (1988). Constituição da República Federativa do Brasil, Brasília, DF: Senado Federal, Centro Gráfico, 1988.

BRASIL. Supremo Tribunal Federal. ADI 3540-1. Relator: Min. Celso de Mello. Brasília, 01 set. 2005. Disponível em: <https://goo.gl/zr7gLv>. Acesso em: 29 jun. 2015.

BUSSINGUER, Elda Coelho de Azevedo. A questão do poder na enfermagem: uma tentativa de compreensão a partir da fenomenologia sociológica de Alfred Schutz. 1991. Livre-docência Universidade Federal do Estado do Rio de Janeiro, Rio de Janeiro, 1991.

BUSSINGUER, Elda Coelho de Azevedo. Ensino jurídico e aprendizagem significativa: uma tentativa de compreensão da tragédia, do direito e da justiça a partir de uma abordagem fenomenológica. In.: MIGUEL, Paula Castello; OLIVEIRA, Juliana Ferrari. Estratégias pedagógicas inovadoras no ensino jurídico. 2. v. Rio de Janeiro: Lumen Juris, 2012.

CAPALBO, Creusa. Fenomenologia e ciências humanas. Rio de Janeiro: Âmbito Cultural Edições Ltda, 1987.

CAPALBO, Creusa. Fenomenologia e ciências humanas. Rio de Janeiro: Âmbito Cultural Edições Ltda, 2008.

CAPALBO, Creusa. Fenomenologia e hermenêutica. Rio de Janeiro: Âmbito Cultural, 1983.

CHAUÍ, Marilena de Souza. Vida e obra. In.: HEIDEGGER, Martin. Conferência e escritos filosóficos. São Paulo: Abril Cultural, 1979.

CUNHA, Antônio Geraldo da. Dicionário etimológico da língua portuguesa. 4. ed. Rio de Janeiro: Lexikon, 2010.

CUNHA, Ricarlos Almagro Vitoriano. Fenomenologia e ciências sociais: a origem comum dos pensamentos de Husserl e Heidegger. In: Cadernos da EMARF, Rio de Janeiro, v. 5, n. 2, p. 1-125, out. 2012/mar. 2013, 2013.

DARTIGUES, André. O que é a fenomenologia? São Paulo: Centauro, 2008. 
ECO, Humberto. Como se faz uma tese em ciências humanas. 13. ed. Lisboa: Editora Presença, 2007.

GUIMARÃES, Aquiles Côrtes. Fenomenologia e direitos humanos. Rio de Janeiro: Lúmen Juris, 2007.

HAIDAR, Rodrigo. Supremo Tribunal Federal reconhece união estável homoafetiva. Consultor Jurídico. Brasília, 5 maio 2011. Disponível em: <https://goo.gl/qPsbh7>. Acesso em: 3 jul. 2015.

HART, Herbert Lionel Adolphus. O conceito de direito. 3. ed. Lisboa: Fundação Calouste Gulbenkian, 2001.

HEIDEGGER, Martin. A questão da técnica. In: Ensaios e conferências. Petrópolis: Vozes, 2002.

HEIDEGGER, Martin. Ser e tempo. 8. ed. Petrópolis: Vozes; Bragança Paulista: Editora Universitária São Francisco, 2013.

HUSSERL, Edmund. A ideia da fenomenologia. Lisboa: Edições 70, 1989.

HUSSERL, Edmund. Investigações lógicas: sexta investigação. São Paulo: Abril Cultural, 1975.

KANT, Immanuel. Crítica da razão pura. 5. ed. Lisboa: Fundação Calouste Gulbenkian, 2001.

KELSEN, Hans. Teoria pura do direito. 7. ed. São Paulo: Martins Fontes, 2006.

LARANJA, Anselmo Laghi. A social democracia de Rui Barbosa e a defesa da positivação de direitos sociais na campanha presidencial de 1919. In: ADEODATO, João Maurício (Org.). Continuidade e originalidade no pensamento jurídico brasileiro: análises retóricas. Curitiba, PR; CRV, 2015.

LÉVINAS, Emmanuel. Descobrindo a existência com Husserl e Heidegger. Lisboa: Instituto Piaget, 1997.

MÜLLER, Friedrich. Teoria estruturante do direito. São Paulo: Editora Revista dos Tribunais, 2008.

ORGANIZAÇÃO DAS NAÇÕES UNIDAS (ONU). Declaração Universal dos Direitos Humanos. UNIC/Rio/005, janeiro 2009. Disponível em: <https://goo.gl/uKU03U>. Acesso em: 3 jul. 2015.

PEDRA, Adriano Sant’Ana. Mutação constitucional. 2. ed. Rio de janeiro: Lúmen Juris, 2013.

PEDRA, Adriano Sant'Anna. As mutações constitucionais e o limite imposto pelo texto da constituição: uma análise da experiência latino-americana. In: Revista Brasileira de Estudos Políticos, Belo Horizonte, n. 101, p. 7-36, jul./dez. 2010.

REALE, Giovanni; ANTISERI, Dario. História da filosofia: do romantismo até nossos dias. 3. v. 5. ed. São Paulo: Paulus, 2001.

RIBEIRO JÚNIOR, João. Introdução à fenomenologia. Campinas: Edicamp, 2003. 
STEIN, Ernildo. Mundo vivido: das vicissitudes e dos usos de um conceito da fenomenologia. Porto Alegre: EDIPUCRS, 2004.

STRECK, Lenio Luiz. Verdade e consenso. 2. ed. Rio de Janeiro: Lumen Juris, 2008.

\section{Anselmo Laghi Laranja}

Graduado em Direito pela Faculdade de Direito de Colatina, Mestre em História pela Universidade Federal do Espírito Santo e Doutorando em Direito e Garantias Fundamentais pela Faculdade de Direito de Vitória. Professor da Faculdade Novo Milênio e juiz de direito (Tribunal de Justiça do Estado do Espírito Santo).E-mail: anselmolaranja@gmail.com

Elda Coelho de Azevedo Bussinguer Graduada em Direito pela Faculdade de Direito de Vitória (FDV), Graduada em Enfermagem e Obstetrícia pela Universidade Federal do Espírito Santo (UFES), Mestre em Direitos e Garantias Fundamentais pela FDV e Mestre em Enfermagem pela Universidade Federal do Rio de Janeiro (UFRJ). Doutora em Bioética pela Universidade de Brasília (UnB). PósDoutoranda em Saúde Coletiva pela UFRJ. Livre Docente pela Universidade do Rio de Janeiro (UniRio). Coordenadora do Programa de Pós-Graduação em Direito da FDV. Coordenadora de Pesquisa da FDV. Professora no Programa de Pós-Graduação em Direito da FDV (Mestrado e Doutorado em Direitos e Garantias Fundamentais). E-mail: pesquisa@fdv.br 